\title{
Comparison of the Effect of Core Stability Exercises and Otago Exercises on Quality of Life in Patients with Stroke
}

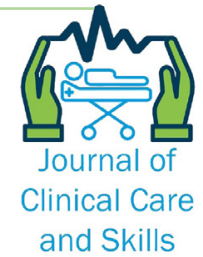

\section{ART ICLE INFO}

\section{Article Type}

Original Research

\section{Authors}

Pirayesh F. ${ }^{1} M S c$

Karimi Z. ${ }^{2} P h D$,

Ghatee M.A. ${ }^{3} P h D$,

Yazdanpanah $\mathrm{P}^{4} M D$,

Razmeh S. ${ }^{5} M D$,

Mohammadhossini S.*1 PhD

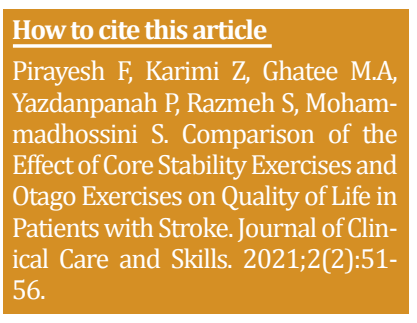

${ }^{1}$ Department of Nursing, School of Nursing, Yasuj University of Medical Sciences, Yasuj, Iran

${ }^{2}$ Department of Operating Room, Para Medicine School, Yasuj University of Medical Sciences, Yasuj, Iran ${ }^{3}$ Cellular \& Molecular Research Center, Yasuj University of Medical Sciences, Yasuj, Iran

${ }^{4}$ Department of Physical Medicine \& Rehabilitation, Yasuj University of Medical Sciences, Yasuj, Iran

${ }^{5}$ Department of Neurology, Yasuj University of Medical Sciences, Yasuj, Iran

\section{*Correspondence}

Address: School of Nursing, Next to Imam Sajad Hospital, Shahid Ghorbanali Jalil St, Yasuj, Iran. Postal Code: 7591994799.

Phone: +98 (74) 33234115

Fax: +98 (74) 33234115

hossini3270@yahoo.com

\section{Article History}

Received: December 10, 2020

Accepted: April 26, 2021

ePublished: June 20, 2021

\section{A B S T R A C T}

Aims Stroke has unforeseen and destructive effects on patients' lives and reduces the quality of life of these patients leading to a decrease in quality of life, stress, and anxiety in these patients and disrupting their daily and daily activities. Therefore, this study aimed to compare the effect of core stability training using Otago exercises on quality of life in patients with stroke.

Materials \& Methods The present clinical trial was conducted on all stroke patients referring to the educational and medical centers of Yasuj University of Medical Sciences in 2020. A total of 69 patients were selected by the convenience sampling method. The samples were randomly assigned to three groups: core stability exercises group (first intervention group, 23 people), Otago exercises group (second intervention group, 23 people), and control group (23 people). For patients in the first intervention group, core stability exercises were performed for 8 weeks and 3 sessions per week, and for patients in the second intervention group, Otago exercises were performed for 8 weeks and 3 sessions per week. No training was given to the control group. Demographic characteristics checklist and stroke SpecificQuality of Life (SS-QOL) were used to collect data before the intervention and one month after the intervention. The collected data were analyzed using SPSS software version 21 and descriptive statistics and Paired T-test, One-way Analysis of Variance, Bonferroni Post Hoc test.

Findings There was no significant difference between the two groups in terms of pain severity and endurance of the flexor muscles at the starting point ( $p>0.05)$. The comparisons of the mean immediately and a week after the intervention were significant $(\mathrm{p}<0.05)$. Before the intervention, there was no statistically significant difference in the overall score of quality of life in the experimental and control groups ( $p>0.001)$. At the end of the intervention, there was a statistically significant difference in the mean score of quality of life between the two groups of core stability and Otago exercises compared with the control group $(\mathrm{p}<0.001)$. After the intervention, the mean total scores of quality of life in the Otago group increased by about 11.86 points compared with the group core stability, and this difference was significant $(\mathrm{p}<0.001)$.

Conclusion e of flexor muscles in patients with non-chronic lower back pain. Both core stability and Otago exercises improved patients' quality of life with stroke, but Otago exercise was more effective than core stability exercises.

\section{Keywords Core Stability; Otago; Exercises; Quality of Life; Stroke}

\section{I T A T I O N L I N K S}

[1] Ctnnb1 transcriptional upregulation compensates ... [2] Stroke-card care to prevent cardiovascular ... [3] Epidemiology and risk factors of stroke in ... [4] Comparison of neurological clinical manifestation ... [5] Quality of life and age following ... [6] Coping strategies and healthrelated ... [7] The effects of balance and gait function ... [8] Indigenizing quality of life: The goodness ... [9] Moving stroke rehabilitation forward ... [10] Hydrotherapy vs. conventional land-based ... [11] The beneficial role of early exercise ... [12] Effects of core stabilization exercises ... [13] Disseminating the Otago exercise ... [14] Does modified Otago Exercise ... [15] The effectiveness of a video-supported ... [16] Effect of Otago exercise program ... [17] The effectiveness of group ... [18] Impact of the fall prevention Otago ... [19] Effects of a falls prevention ... [20] A 6-week hip muscle strengthening ... [21] The combined effectivenes ... [22] Development of a stroke-specific ... [23] Stroke specific quality ... [24] Musculoskeletal deformities-sports ... [25] Effects of three home-based exercise ... [26] Effects of a community-based ... [27] Effects of the Otago exercise program ... [28] Comparison of the effects of 8 weeks ... [29] The effect of a 6-week core stability ... [30] Effect and durability of eight weeks ... 


\section{Introduction}

Stroke is the third leading cause of death and the leading cause of permanent disability worldwide ${ }^{[1]}$. According to the latest reports (2017), stroke was observed in 80.1 million people and caused 6.2 million deaths each year worldwide [2]. Farhoudi et al. in Tabriz in 2019 declared that the prevalence of 120 per 100,000 people for stroke [3].

There are two types of hemorrhagic and ischemic strokes that the former is due to fracture of blood vessels $(20 \%)$, and the latter is due to occlusion of cerebral arteries $(80 \%){ }^{[4]}$. Stroke is a major problem that has a significant impact on health-related quality of life ${ }^{[5]}$ and makes it worse [6]; these patients have a lower quality of life than others ${ }^{[7]}$. According to the World Health Organization, quality of life is defined as people's perception of their position in life in cultural systems and valuation and relation to their goals, expectations, standards, and attitudes [8].

Rehabilitation of people with stroke is done to reduce their disorders and promote their activities participation and [9]. Various rehabilitation methods have been used to improve disabilities after stroke [10]. Exercise training is a regular treatment for stroke patients [11]. The core stability training program is one of these training programs. Core stability exercises are performed to reduce the simultaneous activity of the paraspinal, abdominal, and gluteal muscles and reduce the risk of injury and pain to these muscles. These exercises stimulate the sensory and motor receptors of the muscles and stabilize the spine [12]. Another effective sports intervention is the Otago exercise, which was first designed and evaluated in New Zealand [13]. This program includes strength and balance exercises that can improve mobility, functional balance, the balance of one leg, and lower limb strength and walk ${ }^{[14,15]}$. This safe and cost-effective program is especially effective for people aged 80 years or older [14]. It is also effective in preventing falling [16] and for functional independence and helps to slow the progression of disability [17]. In addition, it is an effective program in pain management ${ }^{[18]}$.

Bjerk et al. showed that the Otago-based falls prevention exercise improved the quality of liferelated health and balance in older adults receiving home care ${ }^{[19]}$. Also, Hoglund et al. showed that pelvic joint strengthening and core stability programs could be useful for improving the quality of life, symptoms, activity, and physical function of people with osteoarthritis of the knee and thigh joint [20]. Studies on the effect of core stability training and Otago training in other patients with chronic disorders show that these exercises are effective in improving their quality of life, indicating the importance of exercise as a treatment.

Various studies are available on stroke patients; however, no study was found in which these exercises were performed comparatively on the quality of life of patients with stroke. Therefore, according to the importance of this disease and its complications affecting society and the importance of exercise as a method of rehabilitation, this study aimed to determine and compare core stability exercises with Otago exercises on the quality of life of patients with stroke.

\section{Materials and Methods}

The statistical population of the present clinical trial consisted of all patients with stroke referring to the educational and medical centers of Yasouj University of Medical Sciences from April to July 2020. The sample size was estimated 16 cases for each group using relevant studies [21], according to the following formula, and considering $\alpha=0.05, \beta=0.2,1-\beta=0.8$, $\mathrm{Si} 2=36, \mathrm{Sc} 2=16, \mathrm{Mi}=40$, and $\mathrm{Mc}=35$ :

$n=\frac{\left(z_{1-\alpha / 2}+z_{1-\beta}\right)^{2}\left(\sigma_{1}^{2}+\sigma_{2}^{2}\right)}{d^{2}}$

Considering the attrition of $40 \%$ for each group, finally, the sample size was regarded as 23 people, and a total of 69 people were selected by the available sampling method. Using the random allocation method, they were divided into three groups: intervention 1 (core stability exercises), intervention 2 (Otago exercises), and control groups. Those aged 40-70 years, diagnosed with ischemic stroke by a neurologist, passing 6 months after the stroke, able to walk independently, able to participate in exercise according to the expert physician, and those who signed the informed consent were included in the study, and people with heart, lung, and neurological disorders and had previously participated in studies similar to the present study were excluded from the study.

The Demographic Characteristics Checklist and the Stroke Specific-Quality of Life (SS-QOL) Questionnaire ${ }^{[22]}$ were used to collect data. SS-QOL was designed by Willams et al. and included 49 questions related to 12 dimensions based on the Likert scale. The score is between 245-49, and the higher the score, the better the quality of life [22]. Mahmoudi et al. this questionnaire has acceptable validity and reliability [23].

This study was registered in the Research Ethics Committee of the Vice Chancellor for Research and Technology of Yasouj University of Medical Sciences. Patients' informed and written consent was obtained before the intervention and after a complete explanation about the purpose of the study. Other ethical considerations were the confidentiality of the information collected, voluntary participation in the study, and the possibility of withdrawal at any stage of the study. The participants of intervention group 1 were subjected to the core stability exercises training, and the participants of intervention group 2 were subjected to the Otago exercises by the 
researcher. Both groups performed the exercises for 8 weeks and 3 individual sessions per week for 30-45 minutes (starting from 30 minutes and reaching 45 minutes in the last weeks); the number of movements and the time of performing increased during eight weeks. Exercises were performed individually in a suitable room (maintaining the principle of patient privacy) in Shahid Beheshti Hospital, Shahid Mofteh Clinic No. 1, and private clinics. The training program of the core stability group (first intervention group) and Otago group (second intervention group) are presented in Tables 1 and 2 . The control group received no intervention. Then, one month after the intervention, participants in all three groups completed the SS-QOL.

The collected data were analyzed using SPSS 21 software at a significance level of 0.05 . One-way analysis of variance (ANOVA) was used for group comparison, paired t-test was used for intragroup comparison, and Bonferroni test was used for pairwise comparison of mean differences.

Table 1) The eight-week training program of the core stability group

\begin{tabular}{|c|c|}
\hline Week & Type of exercise \\
\hline First & $\begin{array}{l}\text { Cat camel stretch, all fours stretch and lifting } \\
\text { one leg, cobra pose, lying on your back and } \\
\text { raising the legs/one leg, and hamstring stretch } \\
\text { on chair }\end{array}$ \\
\hline Second & $\begin{array}{l}\text { Straight Leg Crunch, Cat camel stretch, all fours } \\
\text { stretch and raising one leg, cobra pose, lying on } \\
\text { your back and lifting the legs/one leg, and } \\
\text { hamstring stretch on chair }\end{array}$ \\
\hline Third & $\begin{array}{l}\text { Crunch, bridge exercise, all fours stretch and } \\
\text { raising one leg, cobra pose, lying on your back } \\
\text { and lifting the legs/one leg straight out, and } \\
\text { hamstring stretch on chair }\end{array}$ \\
\hline Fourth & $\begin{array}{l}\text { Crunch, bridge exercise, all fours stretch and } \\
\text { lifting one leg, cobra pose, lying on your back } \\
\text { and lifting the legs/one leg to the opposite hand, } \\
\text { and hamstring stretch on chair }\end{array}$ \\
\hline Fifth & $\begin{array}{l}\text { Reverse Crunch, bridge exercise without } \\
\text { support, all fours stretch and lifting one hand } \\
\text { and one leg, cobra pose, lying on your back and } \\
\text { lifting the leg/legs, and hamstring stretch on the } \\
\text { floor }\end{array}$ \\
\hline Sixth & $\begin{array}{l}\text { Reverse Crunch, bridge exercise without } \\
\text { support, all fours stretch and lifting one hand } \\
\text { and one leg, cobra pose, lying on your back and } \\
\text { lifting the leg/ legs, and hamstring stretch on the } \\
\text { floor }\end{array}$ \\
\hline Sevent & $\begin{array}{l}\text { Reverse Crunch, bridge exercise without } \\
\text { support, all fours stretch and lifting one hand } \\
\text { and one leg, cobra pose, lying on your back and } \\
\text { lifting leg/legs with both hands, and hamstring } \\
\text { stretch on the floor }\end{array}$ \\
\hline Eighth & $\begin{array}{l}\text { Exercise Ball Crunch, bridge exercise without } \\
\text { support, all fours stretch and lifting one hand } \\
\text { and one leg, cobra pose, lying on your back and } \\
\text { lifting leg/legs with a ball, hamstring stretch on } \\
\text { the floor, and stability ball bridge }\end{array}$ \\
\hline
\end{tabular}

Table 2) The eight-week training program of the core stability group [24]

\begin{tabular}{|c|c|}
\hline Week & Type of exercise \\
\hline First & $\begin{array}{l}\text { Walking forward with support, standing on } \\
\text { toe/heel with support, side walking with } \\
\text { support, standing on one foot with support, and } \\
\text { getting up from the chair with both hands }\end{array}$ \\
\hline Second & $\begin{array}{l}\text { Walking forward with support, standing on } \\
\text { toe/heel with support, side walking with } \\
\text { support, standing on one foot with support, and } \\
\text { getting up from the chair with both hands }\end{array}$ \\
\hline Third & $\begin{array}{l}\text { Walking forward without support, standing on } \\
\text { toe/heel without support, side walking without } \\
\text { support, standing on one foot without support, } \\
\text { and getting up from the chair with one hand }\end{array}$ \\
\hline Fourth & $\begin{array}{l}\text { Walking forward without support, standing on } \\
\text { toe/heel without support, side walking without } \\
\text { support, standing on one foot without support, } \\
\text { and getting up from the chair with one hand }\end{array}$ \\
\hline Fifth & $\begin{array}{l}\text { Walking backward with support, walking on } \\
\text { toe/heel with support, walking and turning } \\
\text { around, walking on toe/heel with support, and } \\
\text { getting up from the chair without hands }\end{array}$ \\
\hline Sixth & $\begin{array}{l}\text { Walking backward with support, walking on } \\
\text { toe/heel with support, walking and turning } \\
\text { around, walking on toe/heel with support, and } \\
\text { getting up from the chair without hands }\end{array}$ \\
\hline Sevent & $\begin{array}{l}\text { Walking backward without support, walking on } \\
\text { toe/heel without support, walking and turning } \\
\text { around, walking on toe/heel without support, } \\
\text { and getting up from the chair without hands } \\
\text { using ball }\end{array}$ \\
\hline Eighth & $\begin{array}{l}\text { Walking backward without support using a ball, } \\
\text { walking on toe/heel without support, walking } \\
\text { and turning around using a ball, walking on } \\
\text { toe/heel without support using a ball, and } \\
\text { getting up from the chair without hands using a } \\
\text { ball }\end{array}$ \\
\hline
\end{tabular}

\section{Findings}

A total of 69 patients with stroke were studied. The mean age of participants was $63.81 \pm 6.13$ years, and most of them were male, married, and illiterate (Table 3).

Table 3) Demographic information of the patients with stroke

\begin{tabular}{|c|c|c|}
\hline \multicolumn{2}{|l|}{ Variable } & No. $(\%)$ \\
\hline \multirow{2}{*}{ Gender } & Male & $36(52.2)$ \\
\hline & Female & $33(47.8)$ \\
\hline \multirow{2}{*}{$\begin{array}{l}\text { Marital } \\
\text { status }\end{array}$} & Married & 55 (79.7) \\
\hline & Widow/widower & $14(20.3)$ \\
\hline \multirow{4}{*}{ Education } & Illiterate & $39(56.5)$ \\
\hline & Below diploma & $21(30.5)$ \\
\hline & Diploma & $8(11.6)$ \\
\hline & Above diploma & $1(1.4)$ \\
\hline \multirow{4}{*}{ Occupation } & Housewife & $32(46.4)$ \\
\hline & Manual worker & $4(5.8)$ \\
\hline & Employee & $5(7.2)$ \\
\hline & Others & $28(40.6)$ \\
\hline
\end{tabular}


There was no statistically significant difference in the mean total score of quality of life between participants in the three groups before the intervention $(\mathrm{p}<0.001)$. However, one month after the intervention, the mean total score of quality of life showed a statistically significant difference between the three groups $(\mathrm{p}<0.001)$. The mean total score of quality of life in the intervention group 1 and 2 showed a statistically significant increase after the intervention $(\mathrm{p}<0.001$; Table 4$)$.

Table 4) Comparison of the mean total scores of quality of life in patients with stroke in all three groups

\begin{tabular}{llll}
\hline Total score & $\begin{array}{l}\text { Before the } \\
\text { intervention }\end{array}$ & $\begin{array}{l}\text { After the } \\
\text { intervention }\end{array}$ & $\begin{array}{l}\text { Intragroup } \\
\text { p-value }\end{array}$ \\
\hline $\begin{array}{l}\text { Core } \\
\text { stability } \\
\text { group }\end{array}$ & $163.08 \pm 3.46$ & $182.69 \pm 2.51$ & $<0.001$ \\
$\begin{array}{l}\text { Otago } \\
\text { group }\end{array}$ & $162.82 \pm 3.70$ & $194.56 \pm 2.77$ & $<0.001$ \\
$\begin{array}{l}\text { Control } \\
\text { group }\end{array}$ & $163.39 \pm 3.25$ & $166.86 \pm 16.05$ & 0.32 \\
$\begin{array}{l}\text { Intergroup } \\
\text { p-value }\end{array}$ & 0.85 & $<0.001$ & - \\
\hline
\end{tabular}

The results of pairwise comparisons using the Bonferroni post hoc test showed a significant increase in patients' quality of life in both intervention groups compared with the control group. Also, the mean total score of quality of life in the intervention group 2 (Otago group) compared with the core stability training group increased by about 11.86 points and this difference was significant ( $p<0.001$; Table 5).

Table 5) Comparison of the mean difference (post hoc) of total scores of quality of life after the intervention in patients with stroke in all three groups

\begin{tabular}{ll}
\hline Groups (I-J) & Mean difference \\
\hline Control (J) - core stability (I) & 15.82 \\
Control (J) - Otago (I) & 27.69 \\
Core stability (J)- Otago (I) & 11.86 \\
Otago (J)- core stability (I) & -11.86 \\
Core stability (J)- control (I) & -15.82 \\
Otago (J)- control (I) & -27.69 \\
\hline
\end{tabular}

\section{Discussion}

This study aimed to determine and compare the effect of core stability exercises with Otago exercises on quality of life in patients with stroke. The present study results showed that the mean total score of quality of life patients with stroke increased significantly one month after the research interventions in the core stability and Otago groups. Similar to the present study results, Hager et al. found that home exercise programs (including test and exercise, Otago exercise, and Helsana exercise) had a positive effect on preventing falls in the elderly. Also, the cooperation of physiotherapists and older people to choose exercises to help them increase not only health literacy but also increase exercise enjoyment allowing patients to be more independent [25].
Although the results of these two studies are similar, the mentioned study was performed on the elderly, and interventions lasted for 6 months. Tidman and Skotzke examined the effects of a community-based exercise program on mobility, balance, cognition, sleep, daily activities, and quality of life in patients with Parkinson's disease in a pilot study. Their results showed that although exercise had a positive relationship with performance improvement, this study using a short-term intervention cannot indicate the relationship [26]. The results of this study are not in line with the results of the present study. This inconsistency may be since the type of intervention is not the same in both studies, and there was no control group in the mentioned study. Park and Chang reported that the Otago exercise program is an effective way to improve the effect of falls in elderly patients with stroke [27], which is consistent with the present study results.

Heidari et al. showed that both Swiss-ball core stability training and training using a suspension rope significantly affected the quality of life and reduced pain in women with non-specific chronic low back pain. However, no statistically significant differences were seen between the two protocols. However, due to the effectiveness of most suspension exercises considering mean differences, this difference may be significant if the duration of the protocols is increased [28]. In the mentioned study, similar to the present study, core stability exercises affected the quality of life of women with chronic low back pain. In both studies, the intervention and duration of exercises were similar, and also the quality of life was studied, but a small sample size was considered in this study. In line with the results of the present study, Omidi et al. showed that core stability exercises are effective on the risk of falls as well as the quality of life of blind people and due to the importance of mobility, especially in children with visual impairments, it is recommended that core stability exercises be used as an effective method to maximize physical mobility in this group [29]. Although in the mentioned study, participants had a different disease than the present study, both measured quality of life and reported positive results. Almas et al. showed that core stability exercises and Pilates exercises did not differ much in terms of variables, such as quality of life and visual pain scale; however, there are significant differences in terms of sensory control, and core stability exercises are more effective than Pilates exercises [30], which is not consistent with the results of the present study. In the present study, Otago exercises were more effective in improving quality of life than core stability exercises, which may be due to the research design and different time of evaluation and completion of questionnaires after the intervention.

Although the findings of this study indicated an improvement in the quality of life of patients with stroke, this study also had limitations, including no 
regular face-to-face communication due to the COVID-19 pandemic, individual differences of the participants in answering the questions of the tools, differences in people's innate ability to respond to exercise programs, and differences in psychological support and encouragement of the patient in performing exercises by family members, which all can affect the results of the research and their control was beyond the control of the researcher. Therefore, it is suggested that in future relevant studies, differences and abilities of individuals in performing exercise movements, as well as family support, be examined to determine the most effective protocols to improve the quality of life in people with each type of disease. The findings of this study can also be provided to caregivers, nurses, rehabilitation centers, and physiotherapy to improve the quality of life and take a step towards improving nursing care in this field. Therefore, considering the effectiveness of these exercises and also the satisfaction of patients with stroke, if the results are confirmed by other studies, it is recommended that the healthcare team members should consider implementing these treatments, especially Otago exercises, in the treatment of stroke patients.

\section{Conclusion}

According to the findings of this study, both core stability training and Otago training improved the quality of life of patients with stroke, but the effect of Otago training on the quality of life of stroke patients was greater than core stability training.

Acknowledgments: The authors thank all the patients with stroke who participated in the research and the staff of the educational and medical centers of Yasouj University of Medical Sciences. The Vice-Chancellor for Research of Yasouj University of Medical Sciences is also appreciated for financial and moral support.

Ethical Permissions: This study was approved by the Research Ethics Committee of the Vice-Chancellor for Research and Technology of Yasouj University of Medical Sciences (IR.YUMS.REC.1398.162).

Conflicts of Interests: This article was extracted from a Master's thesis.

Authors' Contribution: Pirayesh F (First Author), Introduction Writer/Main Researcher/Discussion Writer (25\%); Karimi Z (Second Writer), Introduction Writer/Assistant Researcher/Discussion Writer (20\%); Qati MA (third author), Statistical Analyst (15\%); Yazdanpanah P (Fourth Author), Methodologist (10\%); Razmeh S (Fifth Author), Methodologist (10\%); Mohammad Hosseini S (Sixth Author), Introduction Writer/Assistant Researcher/Discussion Writer (20\%).

Funding/Support: This research was supported by the Yasuj University of Medical Sciences.

\section{References}

1- Wang H, Zhou K, Li W, Du J, Xiao J. Ctnnb1 transcriptional upregulation compensates for $\mathrm{Mdm} 2 / \mathrm{p} 53$-mediated $\beta$ - catenin degradation in neutrophils following cardioembolic stroke. Gene. 2021;766:145022.

2- Willeit P, Toell T, Boehme C, Krebs S, Mayer L, Lang C, et al. Stroke-card care to prevent cardiovascular events and improve quality of life after acute ischaemic stroke or TIA: A randomized clinical trial. EClin Med. 2020;16:1-10.

3- Farhoudi M, Pashapour A, Alizadeh M, Ladan A, Mostafaei S. Epidemiology and risk factors of stroke in Tabriz, Iran: A population based study. J Exp Clin Neurosci. 2019;6(1):1-4.

4- Ojaghihaghighi SH, Shams Vahdati S, Mikaeilpour A, Ramouz A. Comparison of neurological clinical manifestation in patients with hemorrhagic and ischemic stroke. World J Emerg Med. 2017;8(1):34-8.

5- Kilkenny MF, Grimley R, Lannin NA. Quality of life and age following stroke. Aging. 2019;11(3):845-6.

6- Lo Buono V, Corallo F, Bramanti P, Marino S. Coping strategies and health-related quality of life after stroke. J Health Psychol. 2017;22(1):16-28.

7- Park J, Kim TH. The effects of balance and gait function on quality of life of stroke patients. Neuro Rehabil. 2019;44(1):37-41.

8- Crouch MC, Skan J, David EJR, Lopez EDS, Prochaska JJ. Indigenizing quality of life: The goodness of life for every Alaska native research study. Appl Res Qual Life. 2020 Jan:1-21.

9- Winters C, Kwakkel G, Van Wegen EEH, Nijland RHM, Veerbeek JM, Meskers CGM. Moving stroke rehabilitation forward: The need to change research. Neuro Rehabil. 2018;43(1):19-30.

10- Zhu Z, Cui L, Yin M, Yu Y, Zhou X, Wang H, et al. Hydrotherapy vs. conventional land-based exercise for improving walking and balance after stroke: A randomized controlled trial. Clin Rehabil. 2016;30(6):587-93.

11- Xing Y, Yang SD, Dong F, Wang MM, Feng YS, Zhang F. The beneficial role of early exercise training following stroke and possible mechanisms. Life Sci. 2018;198:32-7.

12- Narouei S, Barati AH, Akuzawa H, Talebian S, Ghiasi F, Akbari A, et al. Effects of core stabilization exercises on thickness and activity of trunk and hip muscles in subjects with nonspecific chronic low back pain. J Bodyw Mov Ther. 2020;24(4):138-46.

13- Shubert TE, Smith ML, Jiang L, Ory MG. Disseminating the Otago exercise program in the United States: Perceived and actual physical performance improvements from participants. J Appl Gerontol. 2018;37(1):79-98.

14- Martins AC, Santos C, Silva C, Baltazar D, Moreira J, Tavares N. Does modified Otago Exercise Program improves balance in older people? a systematic review. Prev Med Rep. 2018;11:231-9.

15- Benavent-Caballer V, Rosado-Calatayud P, Segura-Orti E, Amer-Cuenca JJ, Lison JF. The effectiveness of a videosupported group-based Otago exercise program on physical performance in community-dwelling older adults: A preliminary study. Physiotherapy. 2016;102(3):280-6.

16- Bai M, Guo Z, Fang P, Jin J. Effect of Otago exercise program on the elderly's falls: A Meta-analysis. Chin J Pract Nurs. 2018;34(4):309-14.

17- Kocic M, Stojanovic Z, Nikolic D, Lazovic M, Grbic R, Dimitrijevic L, et al. The effectiveness of group Otago exercise program on physical function in nursing home residents older than 65 years: A randomized controlled trial. Arch Gerontol Geriatr. 2018;75:112-8.

18- Cederbom S, Arkkukangas $M$. Impact of the fall prevention Otago Exercise Programme on pain among 
community-dwelling older adults: A short-and long-term follow-up study. Clin Interv Aging. 2019;14:721-6.

19- Bjerk M, Brovold T, Skelton DA, Liu-Ambrose T, Bergland A. Effects of a falls prevention exercise programme on health-related quality of life in older home care recipients: A randomised controlled trial. Age Ageing. 2019;48(2):213-9.

20- Hoglund LT, Pontiggia L, Kelly JD. A 6-week hip muscle strengthening and lumbopelvic-hip core stabilization program to improve pain, function, and quality of life in persons with patellofemoral osteoarthritis: A feasibility pilot study. Pilot Feasibility Stud. 2018;4:70.

21-Vincent S, Joseph J. The combined effectiveness of gaze stability exercise and Otago exercise on balance and fall risk in elderly people. Int J Med Exerc Sci. 2017;3(3):390-401.

22- Williams LS, Weinberger M, Harris LE, Clark DO, Biller J. Development of a stroke-specific quality of life scale. Stroke. 1999;30(7):1362-9.

23- Mahmoodi M, Safari A, Vossoughi M, Golbon-Haghighi F, Kamali-Sarvestani M, Ghaem H, et al. Stroke specific quality of life questionnaire: Test of reliability and validity of the Persian version. Iran J Neurol. 2015;14(2):94-100.

24- Mansouri-Mehryan SM. Musculoskeletal deformitiessports injury and corrective exercises. Tehran: MAHVAREH; 2016. [Persian]

25- Hager AGM, Mathieu N, Lenoble-Hoskovec C, Swanenburg J, De Bie R, Hilfiker R. Effects of three home- based exercise programmes regarding falls, quality of life and exercise-adherence in older adults at risk of falling: Protocol for a randomized controlled trial. BMC Geriatr. 2019;19(1):13

26- Tidman M, Skotzke, E. Effects of a community-based exercise program on mobility, balance, cognition, sleep, activities of daily living, and quality of life in PD: A pilot study. Neurodegener Dis Manag. 2020;10(1):27-39.

27- Park Y, Chang M. Effects of the Otago exercise program on fall efficacy, activities of daily living and quality of life in elderly stroke patients. J Phys Ther Sci. 2016;28(1):190-3

28- Heidari RS, Sahebozamani M, Karimi Afshar S. Comparison of the effects of 8 weeks of core stability exercise on ball and sling exercise on the quality of life and pain in the female with non-specific chronic low back pain (NSLBP). J Adv Med Biomed Res. 2018;26(117):44-56. [Persian]

29- Omidi M, Shamsi Majalan A, Karimizadeh Ardakani M, Mansoori MH. The effect of a 6-week core stability exercises on the risk of falling and quality of life in blind people. Phys Treat J. 2019;9(4):227-34. [Persian]

30- Almasi S, Shojaedin S, Karimi Z. Effect and durability of eight weeks of central stability and Pilates exercises on sensory function, quality of life and pain in women with non-specific chronic low back pain. J Anesthesiol Pain. 2020;10(4):36-49. [Persian] 